\title{
Impact of a Stay-at-Home Order on Stroke Admission, Subtype, and Metrics during the COVID-19 Pandemic
}

\author{
Fnu Rameez ${ }^{\text {a }}$ Philip McCarthy ${ }^{a} \quad$ Yao Cheng ${ }^{\text {a }}$ Laurel M. Packard ${ }^{a}$ \\ Alan T. Davis ${ }^{b, c}$ Nabil Wees ${ }^{a}$ Nadeem Khan ${ }^{a}$ Justin Singer ${ }^{a, d}$ \\ Muhib Khan ${ }^{a}$ Jiangyong Min ${ }^{a}$ \\ a Department of Neurosciences and Comprehensive Stroke Center, Spectrum Health \\ and Michigan State University College of Human Medicine, Grand Rapids, MI, USA; \\ ${ }^{\mathrm{b}}$ Spectrum Health Office of Research and Education, Grand Rapids, MI, USA; 'Department \\ of Surgery, Spectrum Health and Michigan State University, Grand Rapids, MI, USA; \\ ${ }^{\mathrm{d}}$ Department of Neurological Surgery, Spectrum Health and Michigan State University, \\ Grand Rapids, MI, USA
}

Keywords

COVID-19 · Stay-at-home order · Stroke admission and subtype · Stroke metrics

\begin{abstract}
Objective: Our study aims to evaluate the impact of a stay-at-home order on stroke metrics during the 2019-novel coronavirus (COVID-19) pandemic. Methods: Data on baseline characteristics, stroke subtype, initial National Institutes of Health Stroke Scale (NIHSS) score, the time between last known well (LKW) to emergency department (ED) arrival, tissue plasminogen activator (tPA) administration, the involvement of large vessel occlusion (LVO), and whether mechanical thrombectomy (MT) was pursued in patients with acute stroke were extracted from 24 March to 23 April 2020 (the time period of a stay-at-home order was placed due to the COVID-19 pandemic as the study group) at a tertiary care hospital in West Michigan, USA, compared with data from 24 March to 23 April 2019 (control group). Results: Our study demonstrated a reduction in cases of acute ischemic stroke (AIS), although this did not reach statistical significance. However, there was an increase in hemorrhagic stroke ( $7.5 \%$ controls vs. $19.2 \%$ study group). The age of stroke patients was significantly younger during the period of the stay-at-home order compared to the control group. We identified a significant overall delay of ED arrivals from LKW in the study group. Additionally, an increased number of AIS patients with LVO in the study group (34.8\%) was found compared to the control group (17.5\%). A significantly increased number of patients received MT in the study group. Additionally, 11 patients were COVID-19 PCR-positive in the study group, 10 with AIS and only 1
\end{abstract}


with hemorrhagic stroke. Patients with COVID-19 had a high incidence of atrial fibrillation and hyperlipidemia. One AIS patient with COVID-19 rapidly developed cytotoxic edema with corresponding elevated inflammatory biomarkers. No statistical significance was noted when stroke subtype, LVO, and MT groups were compared. Conclusions: There was a trend of decreasing AIS admissions during the COVID-19 pandemic. There was also a significantly increased number of AIS patients with LVO who received MT, especially those with COVID-19. We conclude that cytokine storm resulting from SARS-CoV-2 infection might play a role in AIS patients with COVID-19.

(C) 2020 The Author(s)

Published by S. Karger AG, Basel

The first case of novel coronavirus disease 2019 (COVID-19) in the USA was documented on 20 January 2020 [1]. Public health and social measures were recommended by the World Health Organization (WHO) and Centers for Disease Control and Prevention (CDC) to stop or slow down the progression of COVID-19. These include physical distancing between people, reducing and avoiding crowding, closure of nonessential facilities, restriction of movements, and staying at home. These strategies have helped to mitigate some of the impact of the pandemic, including a significant reduction in morbidity and mortality, flatten the peak of disease spread so that health care services are not overwhelmed, and keep the disease burden at a manageable level [2].

The first case of COVID-19 in Michigan was reported on 10 March 2020. Due to an exponential increase in COVID-19 cases in the state, all educational facilities were closed on 16 March 2020, nonessential services on 23 March 2020, and a government-mandated stay-athome order was put in place on 24 March 2020.

With social distancing and the stay-at-home order in place, there was concern that people with medical emergencies were not coming to the emergency department (ED), resulting in a decrease in patient influx, and an increase in at-home mortality. Limited data have been published on the impact of social distancing on stroke emergencies. Correspondence and editorials from China and Europe have highlighted the difficulties in getting care for acute ischemic stroke (AIS) during this pandemic $[3,4]$. In this study, we aimed to determine how the stay-at-home order impacted AIS patients as well as the quality of measures for AIS management.

\section{Methods}

Data Availability and Study Population

A retrospective study was conducted at Spectrum Butterworth Hospital, a tertiary care hospital in West Michigan, MI, USA. Stroke admission data were collected from $24 \mathrm{March}$ to 23 April 2020 to study the impact of the stay-at-home order (study group), and these were compared with data from 24 March to 23 April 2019 (control group). The data collected included age, sex, race, stroke subtype, stroke risk factors, initial National Institutes of Health Stroke Scale (NIHSS) score, the time between last known well (LKW) and hospital emergency department (ED) arrival, tissue plasminogen activator (tPA) administration, the involvement of large vessel occlusion (LVO), and whether mechanical thrombectomy (MT) was performed. A confirmed COVID-19 case was defined as positive result on real-time reverse-transcription polymerase chain reaction (PCR) analysis of throat swab specimens.

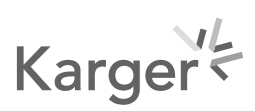




\section{Cerebrovascular Diseases Extra}

\begin{tabular}{l|l}
\hline Cerebrovasc Dis Extra 2020;10:159-165 \\
\hline DOI: $10.1159 / 000512742$ & $\begin{array}{l}\text { @ 2 2020 The Author(s). Published by S. Karger AG, Basel } \\
\text { www.karger.com/cee }\end{array}$ \\
\hline
\end{tabular}

Rameez et al:: Impact of the Stay-at-Home Order on Stroke Metrics during the COVID-19 Pandemic

Table 1. Impact of the stay-at-home order on stroke admission and metrics during the COVID-19 pandemic

\begin{tabular}{|c|c|c|c|}
\hline & $\begin{array}{l}\text { Control period } \\
\text { (24 March to } 23 \text { April 2019) }\end{array}$ & $\begin{array}{l}\text { During stay-at-home order } \\
\text { (24 March to } 23 \text { April 2020) }\end{array}$ & $p$ value \\
\hline Mean age, years & 72.4 & 65.6 & 0.024 \\
\hline Sex & & & 0.253 \\
\hline Male & $41 / 80(51.3 \%)$ & $29 / 47(61.7 \%)$ & \\
\hline Female & $39 / 80(48.8 \%)$ & $18 / 47(38.3 \%)$ & \\
\hline \multicolumn{4}{|l|}{ Race } \\
\hline Caucasian & $74 / 80(92.5 \%)$ & $41 / 47(87.2 \%)$ & 0.399 \\
\hline African-American & $4 / 80(5 \%)$ & $3 / 47(6.4 \%)$ & \\
\hline Hispanic & $2 / 80(2.5 \%)$ & $2 / 47(4.3 \%)$ & \\
\hline Others & $0 / 80$ & $1 / 47(2.1 \%)$ & \\
\hline \multicolumn{4}{|l|}{ Stroke risk factors } \\
\hline Hypertension & $51 / 80(63.8 \%)$ & $35 / 47(74.5 \%)$ & 0.212 \\
\hline Diabetes mellitus & $17 / 80(21.3 \%)$ & $11 / 47(29.8 \%)$ & 0.280 \\
\hline Atrial fibrillation & $18 / 80(22.5 \%)$ & $12 / 47(29.8 \%)$ & 0.698 \\
\hline Smoking history & $17 / 80(21.3 \%)$ & $11 / 47(23.4 \%)$ & 0.777 \\
\hline Low-density lipoprotein notable & $37 / 80(46.3 \%)$ & $25 / 47(53.2 \%)$ & 0.450 \\
\hline A history of prior stroke & $23 / 80(28.8 \%)$ & $12 / 47(25.5 \%)$ & 0.695 \\
\hline \multicolumn{4}{|l|}{ Stroke subtype } \\
\hline Ischemic stroke & $66 / 80(82.5 \%)$ & $37 / 47(78.7 \%)$ & 0.6 \\
\hline Hemorrhagic stroke & $12 / 80(15.0 \%)$ & 9/47 (19.2\%) & 0.050 \\
\hline Subdural hematoma & $2 / 80(2.5 \%)$ & $1 / 47(2.1 \%)$ & 0.629 \\
\hline Subarachnoid hemorrhagia & $0 / 80$ & $0 / 47$ & \\
\hline Initial NIHSS score & & & 0.261 \\
\hline $0-4$ & $37 / 66(56.1 \%)$ & $15 / 36(41.7 \%)$ & \\
\hline $5-15$ & $19 / 66(28.8 \%)$ & $13 / 36(36.1 \%)$ & \\
\hline $16-20$ & $3 / 66(4.6 \%)$ & $5 / 36(13.9 \%)$ & \\
\hline $21-42$ & $7 / 66(10.6 \%)$ & $3 / 36(8.3 \%)$ & \\
\hline Difference in LKW and ED time & & & 0.008 \\
\hline$<4.5 \mathrm{~h}$ & 19/58 (32.8\%) & $19 / 36(52.8 \%)$ & \\
\hline $4.5-12 \mathrm{~h}$ & $11 / 58(19.0 \%)$ & $2 / 36(5.6 \%)$ & \\
\hline $12-24 \mathrm{~h}$ & $9 / 58(15.5 \%)$ & $11 / 36(30.6 \%)$ & \\
\hline$>24 \mathrm{~h}$ & $19 / 58(32.8 \%)$ & 4/36 (11.1\%) & \\
\hline Administration of tPA & $13 / 80(16.3 \%)$ & $14 / 47(29.8 \%)$ & 0.072 \\
\hline tPA time & & & 0.183 \\
\hline$<90$ mins & $0 / 13(0 \%)$ & $4 / 14(28.6 \%)$ & \\
\hline 91-180 mins & $9 / 13(69.2 \%)$ & $7 / 14(50 \%)$ & \\
\hline 181-270 mins & $4 / 13(30.8 \%)$ & $3 / 14(21.4)$ & \\
\hline Large vessel occlusion & $14 / 80(17.5 \%)$ & $16 / 47(34.8 \%)$ & 0.028 \\
\hline Mechanical thrombectomy & $4 / 80(5 \%)$ & $14 / 47(29.8 \%)$ & $<0.001$ \\
\hline
\end{tabular}

Values express $n$, unless otherwise indicated. COVID-19, 2019-novel coronavirus; NIHSS, National Institutes of Health Stroke Scale; LKW, last known well; ED, emergency department; tPA, tissue plasminogen activator.

\section{Statistical Analysis}

Descriptive statistics were used to summarize baseline characteristics. Quantitative data are expressed as either mean \pm SD or median. Nominal data are expressed as percentages. Comparisons for normally distributed quantitative variables were performed using the twotailed $t$ test. Comparisons for nonnormally distributed quantitative variables were performed using the Mann-Whitney U test. Comparisons for nominal variables were performed using the $\chi^{2}$ or Fisher's exact test, as appropriate. All statistical analyses were performed using Stata v15.1 (StataCorp, College Station, TX, USA). Statistical significance was assessed at $p<$ 0.05 . 


\section{Cerebrovascular Diseases Extra}

\begin{tabular}{l}
\hline Cerebrovasc Dis Extra 2020;10:159-165 \\
\hline DOI: 10.1159/000512742
\end{tabular} \begin{tabular}{l}
$\begin{array}{l}\text { @ } 2020 \text { The Author(s). Published by S. Karger AG, Basel } \\
\text { www.karger.com/cee }\end{array}$ \\
\hline
\end{tabular}

Rameez et al.: Impact of the Stay-at-Home Order on Stroke Metrics during the COVID-19 Pandemic

Table 2. Comparison between COVID-19 and non-COVID-19 acute stroke patients when the stay-at-home order was placed during the COVID-19 pandemic

\begin{tabular}{|c|c|c|c|}
\hline & Non-COVID-19 group & COVID-19 group & $p$ value \\
\hline Mean age, years & 63.5 & 72.5 & 0.058 \\
\hline Sex & & & 0.164 \\
\hline Male & $20 / 36(55.6 \%)$ & $9 / 11(81.8 \%)$ & \\
\hline Female & $16 / 36(44.4 \%)$ & $2 / 11(18.2 \%)$ & \\
\hline \multicolumn{4}{|l|}{ Stroke risk factors } \\
\hline Hypertension & $26 / 36(72.2 \%)$ & $9 / 11(81.8 \%)$ & 0.703 \\
\hline Diabetes mellitus & $12 / 36(33.3 \%)$ & $2 / 11(18.2 \%)$ & 0.464 \\
\hline Atrial fibrillation & $5 / 36(13.9 \%)$ & $7 / 11(63.3 \%)$ & 0.003 \\
\hline Smoking history & $10 / 36(27.8 \%)$ & $1 / 11(9.1 \%)$ & 0.525 \\
\hline Low-density lipoprotein notable & $16 / 36(44.4 \%)$ & $9 / 11(81.8 \%)$ & 0.041 \\
\hline A history of prior stroke & $10 / 36(27.8 \%)$ & $2 / 11(18.2 \%)$ & 0.703 \\
\hline \multicolumn{4}{|l|}{ Stroke subtype } \\
\hline Ischemic stroke & $27 / 36(75 \%)$ & $10 / 11(90.9 \%)$ & 0.413 \\
\hline Hemorrhagic stroke & $8 / 36(22.2 \%)$ & $1 / 11(9.1 \%)$ & 0.663 \\
\hline Initial NIHSS score & & & 0.229 \\
\hline $0-4$ & $12 / 27(44.4 \%)$ & $3 / 9(33.3 \%)$ & \\
\hline $5-15$ & $11 / 27(40.7 \%)$ & $2 / 9(22.2 \%)$ & \\
\hline $16-20$ & $2 / 27(7.4 \%)$ & $3 / 9(33.3 \%)$ & \\
\hline $21-42$ & $2 / 27(7.4 \%)$ & $1 / 9(11.1 \%)$ & \\
\hline Difference in LKW and ED time & & & 0.855 \\
\hline$<4.5 \mathrm{~h}$ & $15 / 27(55.6 \%)$ & $4 / 9(44.4 \%)$ & \\
\hline $4.5-12 \mathrm{~h}$ & $2 / 27(7.4 \%)$ & $0 / 9(0 \%)$ & \\
\hline $12-24 \mathrm{~h}$ & $7 / 27(25.9 \%)$ & $4 / 9(44.4 \%)$ & \\
\hline$>24 \mathrm{~h}$ & $3 / 27$ (11.1\%) & $1 / 9(11.1 \%)$ & \\
\hline Administration of tPA & $10 / 36(27.8 \%)$ & $4 / 11(36.4 \%)$ & 0.710 \\
\hline Large vessel occlusion & $12 / 36(33.3 \%)$ & $4 / 11(36.4 \%)$ & $>0.999$ \\
\hline Mechanical thrombectomy & $11 / 36(30.6 \%)$ & $3 / 11(27.3 \%)$ & $>0.999$ \\
\hline
\end{tabular}

Values express $n$, unless otherwise indicated. COVID-19, 2019-novel coronavirus; NIHSS, National Institutes of Health Stroke Scale; LKW, last known well; ED, emergency department; tPA, tissue plasminogen activator.

\section{Results}

A total of 80 patients were admitted to hospital for AIS from 24 March to 23 April 2019. The number of AIS admissions from 24 March to 23 April 2020 was 47, when a stay-at-home order was instituted due to the COVID-19 pandemic (Table 1). The AIS patients in the study group during the COVID-19 pandemic were younger than those the control group (65.6 vs. $72.4 \%$, separately; $p=0.024$ ). There was no significant difference between the 2 groups regarding sex, race, stroke risk factors, initial NIHSS score, or tPA administration. However, we noticed a trend of increasing numbers of hemorrhagic stroke cases during the COVID-19 pandemic when the stay-at-home order was placed as well as an overall delayed ED arrival from LKW. There was an increase in the number of tPA administrations in the study group (29.8\%) versus the control group (16.3\%), but this finding did not reach statistical significance. A significantly higher number of LVO and increasing MT cases were demonstrated in the study group.

Eleven patients were noted to be positive on COVID-19 PCR testing in the study group; 10 had an AIS and only 1 had a hemorrhagic stroke. When compared with non-COVID-19 patients in the study group (Table 2), those positive for COVID-19 were older (63.5 and 72.5 years, respectively), but this was not statistically significant $(p=0.058)$. No statistical 
difference was noted for sex and stroke subtype. For stroke risk factors, a higher percentage of patients in the COVID-19 group were noted to experience atrial fibrillation and hyperlipidemia than in the non-COVID-19 group. No statistical significance was noted when the LVO and MT patients in the 2 groups were compared.

\section{Discussion}

Across the world, social media reported a drop in the number of patients with AIS seeking medical attention during the COVID-19 pandemic; however, solid scientific data remain scarce. Our study demonstrates that while there was a reduction in overall hospital admission for AIS, an increase in the number of stroke patients with LVO was also observed. There was also a slight increase in the number of cases of cerebral hemorrhagia, although the underlying reasons for this are not clear.

A stay-at-home executive order was issued on 24 March 2020 in the state of Michigan to suppress the spread of COVID-19, prevent the state's health care system from being overwhelmed, and thereby avoid needless deaths [5], to be understood reasonably as the reduction in admissions due to the fear of risking COVID-19 exposure in patients with minor stroke-like symptoms coming to hospitals during the pandemic. As the largest comprehensive stroke center in Michigan, we hereby report fewer mild stroke cases. The number of LVO cases increased significantly, however. Recently, there are increased reports of thrombotic complications in patients with COVID-19 [6-8], even in young adults with an absence of common vascular risk factors. Cytokine storm could be the potential mechanism that triggers a hypercoagulable state in patients with COVID-19 [9]. We identified 11 patients as positive for COVID-19 on PCR testing in the study group; 4 of these $(36.4 \%)$ were found to have LVO and underwent MT, significantly more than in the control group (5\%). When comparing COVID-19 and non-COVID-19 patients, the only significant difference was that a higher percentage of COVID-19 patients had atrial fibrillation and hyperlipidemia. Data on the relationship between COVID-19 and hyperlipidemia are limited, but previous data on patients who recovered from severe acute respiratory syndrome coronavirus (SARS-CoV), over 12 years, have shown a higher risk of hyperlipidemia and cardiac abnormalities [10]. Cases of new-onset fibrillation have been reported with COVID-19; however, the exact pathophysiology is unclear [11]. We observed 1 patient with LVO of the right middle cerebral artery, who rapidly developed cytotoxic edema and significantly elevated inflammatory biomarkers. Presumably, what has been called the cytokine storm, as a result of SARS-CoV-2 infection, likely played a role in that patient's rapid radiographic and clinical devastating outcome on day 2 of the AIS.

This study had its limitations. It was a retrospective study with data collection from a single tertiary center. A significant population bias was noted, as roughly $90 \%$ of the patients were Caucasian. Studies have shown a significant association between COVID-19 and ischemic stroke, but there are limited data available on whether social distancing and stay-at-home orders have had an impact on stroke admissions [12]. Our study showed a decrease in stroke admissions, and this pattern of decreased stroke evaluation was also noted by Kansagra et al. [13]. Our study showed a higher percentage of people coming within the tPA window; this could be attributed to a higher NIHSS score prompting acute care, or else have been due to a decrease in patients with mild stroke (NIHSS score $\leq 4$ ). Similar findings were observed by Siegler et al. [14]. We recommend that further multicenter studies be conducted to assess the direct and indirect impact of COVID-19 on stroke emergencies.

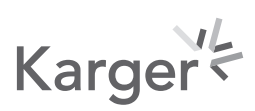




\section{Cerebrovascular \\ Diseases Extra}

\begin{tabular}{l|l}
\hline Cerebrovasc Dis Extra 2020;10:159-165 \\
\hline DOI: 10.1159/000512742 & $\begin{array}{l}\text { (c) 2020 The Author(s). Published by S. Karger AG, Basel } \\
\text { www.karger.com/cee }\end{array}$ \\
\hline
\end{tabular}

Rameez et al:: Impact of the Stay-at-Home Order on Stroke Metrics during the COVID-19 Pandemic

\section{Acknowledgement}

We thank the Spectrum Health Office of Research and Education for helping with statistical support.

\section{Statement of Ethics}

The study was approved by the Spectrum Health Human Research Protection Program and Office of the Institutional Review Board (SH IRB\# 2020-155). This is a retrospective study. A waiver of HIPAA authorization has been approved by the Spectrum IRB per 45 CFR 164.512(i)(2)(ii).

\section{Conflict of Interest Statement}

The authors have no conflicts of interests to declare.

\section{Funding Sources}

This study did not receive any funding.

\section{Author Contributions}

F.R. and J.M contributed to the study design. F.R., P.C., Y.C., and L.M.P. performed the data collection. F.R and A.T.D. performed the statistical analysis. F.R. wrote the manuscript. N.W., N.K., J.S., M.K., and J.S. reviewed and revised the manuscript. J.M. is the leader of this study project who supervised the study.

\section{References}

1 Holshue ML, DeBolt C, Lindquist S, Lofy KH, Wiesman J, Bruce H, et al.; Washington State 2019-nCoV Case Investigation Team. First case of 2019 novel Coronavirus in the United States. N Engl J Med. 2020 Mar;382(10): 929-36.

2 Anderson RM, Heesterbeek H, Klinkenberg D, Hollingsworth TD. How will country-based mitigation measures influence the course of the COVID-19 epidemic? Lancet. 2020 Mar;395(10228):931-4.

3 Morelli N, Rota E, Terracciano C, Immovilli P, Spallazzi M, Colombi D, et al. The baffling case of ischemic stroke disappearance from the casualty department in the COVID-19 era. Eur Neurol. 2020;83:213-15.

4 Zhao J, Rudd A, Liu R. Challenges and potential solutions of stroke care during the Coronavirus disease 2019 (COVID-19) outbreak. Stroke. 2020;51:1356-7.

5 Michigan Legislature. [Internet] Executive Order 2020-42. (COVID-19). 2020. Available from: http://www. legislature.mi.gov/(S(uqsbhoczkpfk1ou51bx2yukc))/mileg.aspx?page=executiveorders

6 Klok FA, Kruip MJ, van der Meer NJ, Arbous MS, Gommers DA, Kant KM, et al. Incidence of thrombotic complications in critically ill ICU patients with COVID-19. Thromb Res. 2020 Jul;191:145-7.

7 Lodigiani C, Iapichino G, Carenzo L, Cecconi M, Ferrazzi P, Sebastian T, et al.; Humanitas COVID-19 Task Force. Venous and arterial thromboembolic complications in COVID-19 patients admitted to an academic hospital in Milan, Italy. Thromb Res. 2020 Jul;191:9-14.

8 Oxley TJ, Mocco J, Majidi S, Kellner CP, Shoirah H, Singh IP, et al. Large-vessel stroke as a presenting feature of Covid-19 in the young. N Engl J Med. 2020 May;382(20):e60.

9 Jose RJ, and Manuel A. COVID-19 cytokine storm: the interplay between inflammation and coagulation. Lancet Respir Med. 202;8(6):e46-7.

\section{Karger'}


10 Zheng YY, Ma YT, Zhang JY, Xie X. COVID-19 and the cardiovascular system. Nat Rev Cardiol. 2020 May;17(5): 259-60.

11 Taha ME, Alsafi W, Taha M, Eljack A, Ibrahim H. Coronavirus Disease and New-Onset Atrial Fibrillation: two Cases. Cureus. 2020 May;12(5):e8066.

12 Beyrouti R, Adams ME, Benjamin L, Cohen H, Farmer SF, Goh YY, et al. Characteristics of ischaemic stroke associated with COVID-19. J Neurol Neurosurg Psychiatry. 2020;91(8):889-91.

13 Kansagra AP, Goyal MS, Hamilton S, Albers GW. Collateral effect of Covid-19 on stroke evaluation in the United States. N Engl J Med. 2020;383:400-1.

14 Siegler JE, Heslin ME, Thau L, Smith A, Jovin TG. Falling stroke rates during COVID-19 pandemic at a comprehensive stroke center. J Stroke Cerebrovasc Dis. 2020 Aug;29(8):104953. 